\title{
A Questionnaire-Based Assessment of Hunger, Speed of Eating and Food Intake in Children with Obesity
}

This article was published in the following Dove Press journal: Diabetes, Metabolic Syndrome and Obesity: Targets and Therapy

\author{
Arnold Slyper' \\ Joelle Shenker ${ }^{2}$ \\ Ariel Israel ${ }^{3}$ \\ 'Pediatric Endocrinology, Clalit Health \\ Services, Jerusalem, Israel; ${ }^{2}$ Department \\ of Pediatrics, Clalit Health Services, \\ Jerusalem, Israel; ${ }^{3}$ Department of Family \\ Medicine, Clalit Health Services, \\ Jerusalem, Israel
}

Purpose: The aim of this study was to investigate the hypothesis that obesity in Israeli children is associated with chronically increased hunger and to examine for persistent abnormalities of satiation and between-meal satiety in these children.

Subjects/Methods: The parents of 200 children with obesity and 100 normal-weight children completed a questionnaire together with their child that rated hunger, food intake at main meal, and speed of eating. Time to hunger from the main meal was also recorded. Children with hunger ratings above 4 on a 7-point scale were considered to have persistent hunger. Food intake ratings at the main meal were used as an approximate indicator of satiation and time from main meal to feeling hunger as an approximate indicator of betweenmeal satiety.

Results: There were marked differences between children with obesity and controls for hunger, food intake at main meal and speed of eating ratings (all $\mathrm{p}<0.001$ ). The difference to time to hunger reached significance after adjusting for age and sex ( $\mathrm{p}=0.048) .41 \%$ of the children with obesity had the highest rating for persistent hunger versus $5 \%$ of controls $(\mathrm{p}<0.001)$.

Conclusion: Persistent hunger, abnormal food intake at the main meal and rapid eating are common in children with obesity and are often of marked degree. These findings could have implications for understanding how pediatric obesity perpetuates itself and even worsens and its resistance to successful treatment over the long term.

Keywords: hunger, obesity, pediatrics, speed of eating

\section{Plain Language Summary}

Self-reported speed of eating is a risk factor for an increase in BMI and obesity in crosssectional and longitudinal studies and a meta-analysis in children and adults. Another metaanalysis showed a relationship between eating speed and energy intake. A previous study by the study group using a questionnaire reported that a large percentage of American children and adolescents with obesity have significantly increased persistent hunger, food intake, and speed of eating compared to normal-weight children. The aims of this study were to confirm these findings in Israeli children using a similar questionnaire and to examine for persistent abnormalities in food intake at the main meal of the day and between-meal satiety. This study found that persistent hunger, increased food intake at the main of the day, rapid eating and decreased satiety are common in children with obesity and are often of marked degree. Although a cross-sectional study, this study supports the hypothesis that what may have begun as a linear relationship between speed of eating and energy intake could become a reinforcing cycle in which hunger and increased speed of eating perpetuate the obesity, lead
Correspondence: Arnold Slyper

Pediatric Specialty Center, Clalit Health

Services, 22 Bnei Brit St, Jerusalem

$95 \mid 4622$, Israel

Tel +97258578 8844

Email arnoldslyper@yahoo.com 
to resistance to successful treatment and continuing excessive weight gain in many obese children.

\section{Introduction}

Relationships between speed of eating and indices of obesity have been well documented for adults and children. The association between increased self-reported eating rate and indices of obesity in adults was the subject of a systemic review and meta-analysis by Ohkuma et $\mathrm{al}^{1}$ that included 12 cross-sectional and 3 longitudinal studies. Mean difference in BMI between individuals eating quickly and those eating slowly was $1.78 \mathrm{~kg} / \mathrm{m}^{2}$, and the pooled odds ratio for the presence of obesity from eating quickly was 2.15 (95\% confidence interval 1.84-2.51). Several large cross-sectional pediatric studies, particularly from Asia, found eating speed to be significantly associated with BMI. $^{2-6}$ A strong relationship between selfreported speed of eating and subsequent BMI has also been shown in pediatric longitudinal studies. ${ }^{7-9}$ In addition, there appears to be a significant genetic basis to speed of eating as determined from studies on twin children. ${ }^{10}$ Nevertheless, to our knowledge, other aspects of abnormal eating behavior, such as chronic hunger, a persistently increased intake at the main meal of the day and a chronic disturbance of satiety have not been reported in the literature using self-reported scales.

It was observed by the principal investigator of this study that many parents of children with obesity seen in his pediatric endocrine practice in the US complained that their offspring were excessively hungry for much of the time and that this was interfering with compliance with dietary management and successful weight control. A preliminary study was therefore carried out in his practice using a questionnaire that the parents and child were asked to complete together and this was subsequently reported. $^{11}$ A unique finding of this study was that a large percentage of children and adolescents with obesity had significantly increased persistent hunger, as well as increased food intake and speed of eating compared to normal-weight children. Because of the possible implications of these findings in terms of understanding the perpetuation and worsening of pediatric obesity, a larger and more comprehensive study was performed in Israeli children with obesity using a questionnaire with a 7-point scale rather than a 4-point scale.

The aims of this study were to confirm the previous findings of persistently increased hunger and speed of eating in children with obesity and thereby provide support to the hypothesis that pediatric obesity is commonly associated with increased chronic hunger. Other aims were to examine for persistent abnormalities of food intake at the main meal of the day and time to feeling hunger from the main meal of the day in these children. Food intake at the main meal of the day could be regarded as an approximate indicator of satiation. Satiation describes the state leading to meal termination. $^{12}$ The time interval to feeling hunger after the main meal of the day was included in the questionnaire as an approximate indicator of usual between-meal satiety. Satiety is the state whereby further eating is inhibited by fullness until the next meal. ${ }^{12}$

\section{Methods}

This was a cross-sectional study performed in clinics of the health fund Clalit Health Services in Jerusalem, Israel. Subjects were 200 children and adolescents with obesity evaluated consecutively in the health fund pediatric weight control clinic. This included an evaluation of the etiology of their obesity, a nutrition evaluation, and discussion as to treatment. All subjects with obesity had a BMI z-score greater than the 95th percentile for age using the US Center for Disease Control and Prevention BMI standards. ${ }^{13}$ They were weighed and measured with their clothes but without their shoes. Exclusion criteria were a medical condition or receiving medication likely to affect weight or appetite. Comorbidities such as hypertension, hyperlipidemia and type 2 diabetes were not regarded as exclusion criteria. Controls constituted age- and sexmatched normal-weight children with a BMI z-score less than the 75th percentile for age seen in a Clalit Health Services primary care pediatric practice in a typical suburb of Jerusalem. Similar exclusion criteria were applied to the controls as the subjects with obesity. Because of its previously demonstrated clinical usefulness, a one-page food frequency questionnaire has been routinely administered in Hebrew or Arabic to all patients seen in the weight control clinic at their initial and follow-up physician visits since its inception, and this questionnaire includes questions regarding eating behavior. The outpatient nurse provides the questionnaire to the parents and requests the accompanying adult or adults to fill in the questionnaire together with their offspring prior to being seen by the physician. If the child is too young to provide any input, the parents alone complete the questionnaire. Families are asked to grade the child's hunger level, food intake at the single main meal of the day, and speed of eating of their offspring on a1 to 7-point scale. The rating system for hunger 
is 1 "much less hunger than normal," 4 "normal hunger," and 7 "hungry for most of the time." The rating system for food intake at the main meal of the day is 1 "less than average," 4 "reasonable amount," and 7 "more than average." Children with hunger ratings above 4 are considered to have persistent hunger. Speed of eating is rated as 1 "very slowly," 4 "reasonable speed," and 7 "very fast." Families are also asked to assess how long after their child's main meal of the day he or she again feels hunger. Because the food frequency questionnaire for specific food items has been improved since this study was performed, this data is not included in this report. The Helsinki Committee of Clalit Health Services at Meir Hospital which complies with the Declaration of Helsinki approved the retrospective evaluation of questionnaires provided to families of children with obesity in the clinic and the administration of the same questionnaire with a consent section to normal-weight controls. Written informed consent was provided by the parents/legal guardians for all children participating as controls in this study.

\section{Statistics}

Baseline characteristics of the cohort were assessed using standard descriptive statistics. Ratings for (1) hunger, (2) food intake, (3) speed of eating, and (4) time to hunger were each compared between the two groups using a twotailed Wilcoxon test. In addition, in order to ascertain that the differences in ratings observed between the two groups were not due to differences in age and sex, multivariable ordinal regression analyses were performed, for each rating, with regard to obese status, adjusted for age, sex, and an interaction term for sex together with the obese status, aimed to assess whether the link between each rating to obesity was different in males and females. For comparisons of categorical data, the Fisher exact test was used. Correlation coefficients and the significance of the association between pairs of features were estimated using Spearman's method. All statistical analyses were performed with $\mathrm{R}$ software version 3.5.1 (R Foundation for Statistical Computing).

\section{Results}

The anthropometric characteristics and eating behavior of the children with obesity and controls are shown in Table 1. It can be seen that patients and controls were well balanced with respect to age and sex as per the study design. The age range of the patients with obesity was 3.9 to 18.1 years and 4.9 to 17.6 years for the normal-weight controls.
Table I Characteristics and Eating Behavior of the Children with Obesity and Normal-Weight Controls

\begin{tabular}{|c|c|c|c|}
\hline Clinical Values & $\begin{array}{l}\text { Subjects } \\
\text { with } \\
\text { Obesity }\end{array}$ & $\begin{array}{l}\text { Normal } \\
\text { Weight } \\
\text { Controls }\end{array}$ & P-value \\
\hline Number of subjects & 200 & 100 & \\
\hline $\begin{array}{l}\text { Mean age (decimal years), } \\
\text { mean (SD) }\end{array}$ & II.I (3.7) & II.I (3.2) & NS \\
\hline Sex distribution \% (F/M) & $57.3 / 42.7$ & $47 / 53$ & NS \\
\hline BMI z-score, mean (SD) & $\begin{array}{l}2.33 \\
(0.40)\end{array}$ & $\begin{array}{l}-0.42 \\
(0.73)\end{array}$ & $<0.001$ \\
\hline $\begin{array}{l}\text { Hunger ratings ( } I-7) \text {, mean } \\
\text { (SD) }\end{array}$ & $\begin{array}{l}5.63 \\
(1.35)\end{array}$ & $4.28(1.12)$ & $<0.001$ \\
\hline $\begin{array}{l}\text { Ratings for food intake at } \\
\text { main meal rating }(I-7) \text {, mean } \\
(S D)\end{array}$ & $\begin{array}{l}5.20 \\
(1.35)\end{array}$ & $3.66(1.07)$ & $<0.001$ \\
\hline $\begin{array}{l}\text { Ratings for speed of eating } \\
(I-7), \text { mean (SD) }\end{array}$ & $\begin{array}{l}4.86 \\
(1.68)\end{array}$ & $3.97(1.29)$ & $<0.001$ \\
\hline $\begin{array}{l}\text { Time to hunger from main } \\
\text { meal (hours), median } \\
\text { [interquartile range] }\end{array}$ & $\begin{array}{l}2.0 \\
{[1.0-3.0]}\end{array}$ & $\begin{array}{l}2.5 \\
{[1.5-3.5]}\end{array}$ & NS \\
\hline
\end{tabular}

Note: Subjects with obesity had a BMI s-score greater than the 95th percentile for age and controls a BMI z-score less than the 75th percentile for age. Abbreviations: F/M, female/male; NS, non-significant.

A marked difference was found between the children with obesity and the normal-weight controls with respect to ratings for hunger, food intake at main meal and speed of eating. The mean of the hunger ratings for the children with obesity (mean, SD) was 5.63 (1.35) versus 4.28 (1.12) for the controls $(p<0.001)$, mean of the ratings for food intake at their main meal for the children with obesity was 5.20 (1.35) versus 3.66 (1.07) for the controls $(p<0.001)$, and mean of the ratings for speed of eating for the children with obesity was 4.86 (1.68) versus 3.97 (1.29) for the controls $(\mathrm{p}<0.001)$. In addition, a shorter time to hunger (in hours) from the main meal was observed for the children with obesity, with a median of 2.0 and an interquartile range [IQR] of [1.0-3.0] versus 2.5 [1.5-3.5] for the controls, although this difference did not reach statistical significance $(\mathrm{p}=0.08)$.

Further analysis showed that $41 \%$ of families of children with obesity admitted that their offspring had the highest rating for hunger, namely "hunger for most of the time" versus only $5 \%$ of the normal weight children $(p<0.001)$, and an abnormal hunger rating of $>4$ was recorded for $71 \%$ of the children with obesity versus $34 \%$ of the children with 
a normal weight $(\mathrm{p}<0.001)$. Of the children with obesity, $26 \%$ had the highest rating for food intake at their main meal versus $0 \%$ of controls $(p<0.001)$, and $60 \%$ of the patients with obesity had a food intake rating at their main meal of $>4$ compared to $13 \%$ of controls $(p<0.001)$. Twenty six percent of the children with obesity had the highest rating for speed of eating versus $5 \%$ of controls $(\mathrm{p}<0.001)$, and $49 \%$ of the children with obesity had a speed of eating rating of $>4$ versus $19 \%$ of controls $(p<0.001)$.

In order to account for the wide age range of the patients and controls, multivariable ordinal regression analyses were performed adjusting for age and sex (see Table 2). Differences in the variables tested remained significant in multivariable models adjusted for age and sex. Interestingly, a significant interaction was found between sex and obesity with respect to speed of eating and intake at the main meal, with male children with obesity eating significantly faster and eating more at their main meal than

Table 2 Multivariable Ordinal Regression Analyses for Ratings for Hunger (I), Food Intake at Main Meal (2), Speed of Eating (3), and Time to Hunger from Main Meal (Hours) (4), Adjusted for Age and Sex, and Sex/Obesity Interaction

\begin{tabular}{|c|c|c|c|c|}
\hline & \multicolumn{4}{|c|}{ Dependent Variable } \\
\hline & Hunger & $\begin{array}{l}\text { Main } \\
\text { Meal }\end{array}$ & $\begin{array}{l}\text { Speed of } \\
\text { Eating }\end{array}$ & $\begin{array}{l}\text { Time to } \\
\text { Hunger }\end{array}$ \\
\hline & (I) & (2) & (3) & (4) \\
\hline \multirow{3}{*}{ Obesity } & 1.997 & 3.006 & 1.907 & -0.624 \\
\hline & $\begin{array}{l}(1.317, \\
2.677)\end{array}$ & $\begin{array}{l}(2.246, \\
3.766)\end{array}$ & $\begin{array}{l}(1.234, \\
2.580)\end{array}$ & $\begin{array}{l}(-1.246 \\
-0.001)\end{array}$ \\
\hline & $\mathrm{P}<0.000 \mathrm{I}$ & $P<0.0001$ & $P<0.0001$ & $p=0.050$ \\
\hline \multirow{3}{*}{ Age } & -0.022 & -0.017 & -0.001 & 0.113 \\
\hline & $\begin{array}{l}(-0.080 \\
0.037)\end{array}$ & $\begin{array}{l}(-0.076 \\
0.042)\end{array}$ & $\begin{array}{l}(-0.06 \mathrm{I}, \\
0.058)\end{array}$ & $\begin{array}{l}(0.05 I, \\
0.176)\end{array}$ \\
\hline & $p=0.467$ & $p=0.572$ & $p=0.969$ & $P=0.0004$ \\
\hline \multirow{3}{*}{ Sex female } & 0.437 & 0.509 & 0.458 & -0.511 \\
\hline & $\begin{array}{l}(-0.307 \\
\text { I. } 181)\end{array}$ & $\begin{array}{l}(-0.259 \\
\text { I.278) }\end{array}$ & $\begin{array}{l}(-0.271 \\
I .187)\end{array}$ & $\begin{array}{l}(-1.233 \\
0.211)\end{array}$ \\
\hline & $p=0.250$ & $p=0.194$ & $p=0.219$ & $P=0.166$ \\
\hline $\begin{array}{l}\text { Interaction } \\
\text { term }\end{array}$ & -0.332 & -1.112 & -1.288 & 0.514 \\
\hline $\begin{array}{l}\text { Sex female } \\
\text { with }\end{array}$ & $\begin{array}{l}(-1.239 \\
0.575)\end{array}$ & $\begin{array}{l}(-2.043 \\
-0.181)\end{array}$ & $\begin{array}{l}(-2.196 \\
-0.381)\end{array}$ & $\begin{array}{l}(-0.37 \mathrm{I}, \\
\text { I.399) }\end{array}$ \\
\hline Obesity & $p=0.474$ & $p=0.020$ & $p=0.006$ & $p=0.255$ \\
\hline
\end{tabular}

their female counterparts $(\mathrm{p}<0.001)$, while no significant association with sex alone was apparent. There was also a significant association between age and time to hunger from the main meal, with the younger patients with obesity displaying a reduced time to hunger $(p<0.001)$, while no interaction with age was apparent for the other variables. In this adjusted regression analysis, the difference observed between children with obesity and controls with respect to time to hunger from the main meal did reach statistical significance $(\mathrm{p}=0.050)$.

Figure $1 \mathrm{~A}-\mathrm{D}$ show the percentages of ratings for the children and adolescents with obesity and the control group for hunger, food intake at main meal and speed of eating, and also time to hunger from the main meal. For the control subjects, hunger, food intake at main meal and speed of eating displayed a distribution centered around 4 . In the children with obesity, a large peak was observed for a rating of 7 for hunger (Figure 1A), and peaks around 7 were also seen for food intake at main meal (Figure 1B) and speed of eating (Figure 1C). In addition, a shorter time to hunger from the main meal was observed in the children with obesity compared to controls (Figure 1D), with a time to hunger of less than two hours being reported in a greater proportion of the patients with obesity, whereas a time to hunger greater than 3 hours was reported in a greater proportion of the controls.

For all subjects combined, BMI z-score was significantly correlated with hunger $(r=0.43, p<0.001)$, food intake at the main meal of the day $(\mathrm{r}=0.51, \mathrm{p}<0.001)$, and speed of eating $(\mathrm{r}=0.30, \mathrm{p}<0.001)$, and inversely correlated to time to hunger from the main meal of the day $(\mathrm{r}=$ $-0.16, p<0.01)$. Hunger was significantly correlated with food intake at main meal $(\mathrm{r}=0.50, \mathrm{p}<0.001)$ and speed of eating $(r=0.33, p<0.001)$, and inversely correlated with time to hunger from the main meal $(-0.45, \mathrm{p}<0.001)$. Time to hunger from the main meal was also significantly inversely correlated with speed of eating $(\mathrm{r}=-0.19$, $\mathrm{p}=0.001)$, as was intake at the main meal $(\mathrm{r}=-0.19$, $\mathrm{p}=0.002$ ).

\section{Discussion}

Using a questionnaire, we have demonstrated marked differences between Israeli children and adolescents with obesity compared to age- and sex-matched controls with normal weight with respect to ratings for persistent hunger, usual food intake at the main meal of the day, and usual speed of eating. Time to hunger from the main meal of the day was also shorter in the children with obesity than 

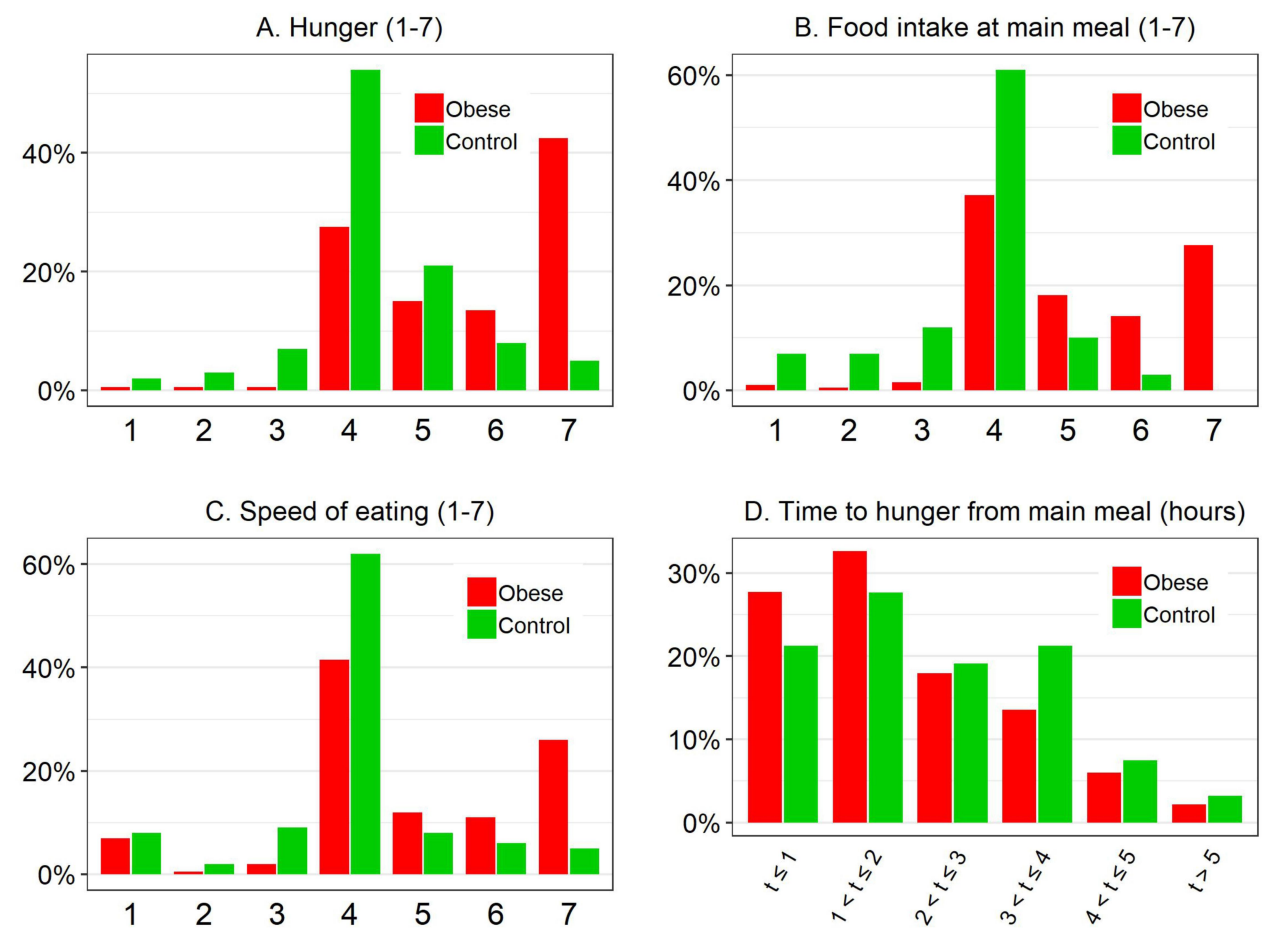

Figure I (A-D) Percentages for ratings for hunger, food intake at main meal and speed of eating, and time to hunger from main meal in hours for children and adolescents with obesity and normal weight controls.

for matched controls and this difference almost reached significance, and did reach significance in a regression analysis adjusted for age and sex. These results therefore provide support to the notion that children with obesity show greater hunger, greater food intake at the main meal of the day and faster eating than normal-weight children. A shorter time to hunger after the main meal is also a feature of pediatric obesity, although it is a less prominent feature, displays age-dependency, and is seen particularly in children with marked hunger. Our observation that persistent hunger is common in children with obesity has not, to our knowledge, been generally recognized. Of note is the extreme nature of the hunger, fast eating and increased eating at the main meal of the day in many of the patients with obesity studied, as evidenced by the families providing the highest ratings for these variables on the questionnaire.

On the regression analysis, we also found a gender interaction for speed of eating and food intake at the main meal, with male children with obesity eating significantly faster than female children with obesity and having an increased food intake, differences which were not apparent in the controls. Zijlstra et $\mathrm{al}^{14}$ found that ad libitum intake and eating rate for a test meal were significantly higher in normal-weight men than normal-weight women. Barkeling et $\mathrm{al}^{15}$ found that energy intake was greater in adult males than adults females. In normalweight men this was because they ate longer and in men with obesity because they ate faster. Nevertheless, to our knowledge, increased speed of eating and increased food intake in male children with obesity in comparison to female children with obesity has not previously been described.

A meta-analysis of 22 studies by Robinson et $\mathrm{al}^{16}$ demonstrated a relationship between eating speed and energy intake. In the studies analyzed, subjects were of any age, eating rate was manipulated, and the effect of doing this on concurrent energy intake, later self-reported hunger, or both were observed. This meta-analysis, plus the studies on self-reported speed of eating previously mentioned, and in particular the longitudinal studies, suggest the possibility of a causal relationship between increased speed of eating and indices of obesity. ${ }^{2-9}$ Although this was a cross-sectional study, the importance of our findings is that they raise the possibility that the triad of chronic hunger, a persistently high eating rate and increased food intake found in a large percentage of the children with obesity in this study indicates that what may have begun as a linear relationship between speed of eating and energy intake has now become a reinforcing 
cycle that could contribute to perpetuation of the obesity, to resistance over the long term to successful treatment, and in many instances to continuing excessive weight gain. An excessive degree of hunger, for example, may lead to hedonic desires for high calorie foods. These are frequently ultra-processed foods that are soft in texture, provide poor satiation and are eaten quickly. ${ }^{17,18}$ Poor satiation may also favor large portion sizes. These may be consumed with a larger bite size and hence with an increased eating rate. ${ }^{19}$

We also suggest that the simple questions developed for this study may have utility in clinical practice for readily identifying those children with obesity who have marked degrees of hunger and marked speed of eating and satiation abnormalities. The importance of this is that the obesity of such children may not respond well to caloric restriction with behavioral modification alone, and attention also needs to be focused on their underlying hunger. ${ }^{20}$

A report of persistent hunger reaches into the area of food hedonics, and specifically food wanting, which can be defined as the drive to eat triggered by a food cue beyond the need for energy homeostasis. ${ }^{21}$ It could be argued that this is a highly subjective feeling and that hunger ratings from the questionnaire we administered have little objective value, particularly in children. However, we suggest that the ratings in this questionnaire do have considerable value. This is because the parents were asked to complete the questionnaire together with their offspring. It is likely that many of the older children with obesity had sufficient insight to appreciate that their hedonic desire for food at meals was different from that of their normal-weight friends and acquaintances. The parents, on the other hand, may have answered this question from a different perspective, in that their ratings could have included the feedback they frequently obtained from their child about he or she still being hungry despite being offered an adequate amount of food, their observations of their child's food intake, speed of eating and between-meal satiety, and their frequent struggles with their child over his or her desire for additional food. In other words, their rating graded their child's behavior in relation to hunger. The questions in this questionnaire were used clinically, and it is our impression that the families had no problem understanding the questions on eating behavior, including that on hunger, and none of these questions were left blank. It is our impression, therefore, that this combined assessment by parent and child is a meaningful reflection of a child's drive to eat when presented with food. In addition, ratings for hunger, food intake at the main meal and speed of eating were significantly inversely correlated with between-meal satiety. Time to hunger from the main meal can be considered a somewhat more precise value than ratings for eating behavior, being a number that can be readily agreed upon by parent and child. In addition, the fact that the highest rating for hunger was written as "hungry for most of the time" would have excluded hedonic eating related to specific food items or the child being usually hungry at specific times of the day.

Self-reported scales regarding hunger and fullness have been used extensively in feeding studies in adults, and although correlations are of low magnitude they do significantly predict subsequent energy intake in this type of experimental setting. ${ }^{22}$ The same variables analyzed in our questionnaire could, of course, be measured during a monitored test meal together with appetite scores. Nevertheless, eating behavior during a single test meal may not always reflect the chronic situation, in that the experimental situation is itself open to additional variables, particularly in children, such as the extent of liking of the test meal, the nature of the test meal, the interference of the monitoring equipment with normal eating, and the absence of socialization that would otherwise effect meal duration. ${ }^{23}$ We therefore suggest that despite its imprecision, the type of questionnaire we have administered is an adequate way for assessing persistent hunger and satiation abnormalities and is open to parental and self-observation in a similar manner to a chronic speed of eating abnormality. The finding of increased hunger in two pediatric studies, although performed in different countries, also reflects favorably on this type of question. ${ }^{11}$

It could be argued that some parents of the children with obesity would have difficulty estimating what constitutes a normal situation for speed of eating and food intake, as they themselves may have abnormal eating behavior as a result of their own obesity. Nevertheless, we suggest that parents of children with obesity have ample opportunity to observe the differences between their child's eating behavior compared to normal-weight family members, including siblings, as well as their child's friends and schoolmates.

Another possible concern is whether the children with obesity in this study are truly representative of the obese pediatric population in Israel. However, there is reason to believe that these children are representative of the pediatric obese, at least in Jerusalem and its immediate referral 
area. Firstly, this study was performed in a community health-fund pediatric weight-control clinic and not in a hospital-based center. Secondly, all patients were referred by primary care physicians from the health fund who had been encouraged to refer all their pediatric patients with obesity to this clinic, with the only criteria for referral being excessive weight gain. With respect to the controls, they were recruited from a single representative primary care pediatric office in Jerusalem. Moreover, ratings for hunger, food eaten at the main meal and speed of eating for the control subjects display an approximately normal distribution centered around an average rating of 4 (Figure $1 \mathrm{~A}-\mathrm{C}$ ) providing additional assurance that our control group reflects a normal pediatric population. The 75th percentile for BMI z-score was chosen as the upper limit for the controls, as in our previous study in the United States, so as to exclude children who were overweight or who were trending into the overweight category.

\section{Conclusion}

In conclusion, we have demonstrated that the parents of a majority of children with obesity attending a community health-fund weight-control clinic in Israel report the presence of persistently increased hunger, increased food intake at the main meal of the day, and increased speed of eating in their offspring compared to normal-weight children, and these features are often present to a marked degree. Time to hunger after the main meal is also significantly abnormal in these children, although this is not as prominent a feature as their food intake abnormality and it is age-dependent. Although a cross-sectional study from which causality cannot be determined, we hypothesize that the features we have described may lead to the development of a self-perpetuating cycle that may contribute to persistence of obesity, resistance over the long-term to successful treatment, and to continuing excessive weight gain.

\section{Author Contributions}

AS conceived this study. AS and JS collected the data. AS and AI analyzed the data. AS and AI were responsible for devising the tables and figures. All authors made substantial contributions to conception and design, acquisition of data, or analysis and interpretation of data; took part in drafting the article or revising it critically for important intellectual content; agreed to submit to the current journal; gave final approval of the version to be published; and agree to be accountable for all aspects of the work.

\section{Disclosure}

The authors Arnold Slyper, MD, Joelle Shenker, MD and Ariel Israel MD, Ph.D. report no conflicts of interest for this work and state that no competing financial interests exist to the work described.

This research did not receive any specific grant from funding agencies in the public, commercial, or not-forprofit sectors.

\section{References}

1. Ohkuma T, Hirakawa Y, Nakamura U, Kiyohara Y, Kitazono T, Ninomiya T. Association between eating rate and obesity: a systematic review and meta-analysis. Int $J$ Obes (Lond). 2015;39:1589-1596. doi:10.1038/ijo.2015.96

2. Liu S, Zhang J, Ma J, et al. Synergistic interaction between bedtime and eating speed in predicting overweight and obesity in Chinese preschool-aged children. Aging. 2019;11:2127-2137. doi:10.18632/ aging.101906

3. Lin M, Pan L, Tang L, Jiang J, Wang Y, Jin R. Association of eating speed and energy intake of main meals with overweight in Chinese pre-school children. Public Health Nutr. 2014;17:2029-2036. doi:10.1017/S1368980013002176

4. Zhang T, Cai L, Ma L, Jing J, Chen Y, Ma J. The prevalence of obesity and influence of early life and behavioral factors on obesity in Chinese children in Guangzhou. BMC Public Health. 2016;16:954. doi:10.1186/s12889-016-3599-3

5. Zeng X, Cai L, Ma J, Jing J, Chen Y. Eating fast is positively associated with general and abdominal obesity among Chinese children: a national survey. Sci Rep. 2018;8:14362. doi:10.1038/s41598018-32498-9

6. Ochiai H, Shirasawa T, Ohtsu T, et al. Eating behaviors and overweight among adolescents: a population-based survey in Japan. J Obes. 2013:717942. Doi:10.1155/2013/717942

7. Yamagishi K, Sairenchi T, Sawada N, et al. Impact of speed-eating habit on subsequent body mass index and blood pressure among schoolchildren - The Ibaraki Children's Cohort Study (IBACHIL). Circ J. 2018;82:419-422. doi:10.1253/circj.CJ-17-0287

8. Ochiai H, Shirasawa T, Nanri H, Nishimura R, Hoshino $H$, Kokaze A. Relationship between eating quickly and overweight: a cohort study of schoolchildren in Japan. Acta Med Okayama. 2018;72:121-128. doi:10.18926/AMO/55852

9. Ochiai H, Shirasawa T, Ohtsu T, et al. The impact of eating quickly on anthropometric variables among schoolgirls: a prospective cohort study in Japan. Eur J Public Health. 2014;24:691-695. doi:10.1093/ eurpub/ckt120

10. Berkowitz RI, Moore RH, Faith MS, Stallings VA, Kral TV, Stunkard AJ. Identification of an obese eating style in 4-year-old children born at high and low risk for obesity. Obesity (Silver Spring). 2010;18:505-512. doi:10.1038/oby.2009.299

11. Slyper AH, Kopfer K, Huang W-M, Re'em Y. Increased hunger and speed of eating in obese children and adolescents. $J$ Pediatr Endocrinol Metab. 2014;27:413-417. doi:10.1515/jpem-2013-0271

12. Benelam B. Satiation, satiety and the effects on eating behavior. Nutr Bull. 2009;34:126-173.

13. Healthy Weight. Centers for disease control and prevention. BMI percentile calculator for child and teen. Available from: https:// www.cdc.gov/healthyweight/bmi/calculator.html.

14. Zijlstra N, Bukman AJ, Mars M, Stafleu A, Ruijschop RM, de Graaf C. Eating behaviour and retro-nasal aroma release in normal-weight and overweight adults: a pilot study. $\mathrm{Br} J \mathrm{Nutr}$. 2011;106:297-306. doi:10.1017/S0007114511000146 
15. Barkeling B, Rössner S, Sjöberg A. Methodological studies on single meal food intake characteristics in normal weight and obese men and women. Int J Obes Relat Metab Disord. 1995;19:284-290.

16. Robinson E, Almiron-Roig E, Rutters F, et al. A systematic review and meta-analysis examining the effect of eating rate on energy intake and hunger. Am J Clin Nutr. 2014;100:123-151. doi:10.3945/ ajen.113.081745

17. van den Boer J, Werts M, Siebelink E, de Graaf C, Mars M. The availability of slow and fast calories in the dutch diet: the current situation and opportunities for interventions. Foods. 2017;6(10):E87. doi: $10.3390 /$ foods6100087

18. Fardet A. Minimally processed foods are more satiating and less hyperglycemic than ultra-processed foods: a preliminary study with 98 ready-to-eat foods. Food Funct. 2016;7:2338-2346. doi:10.1039/ c6fo00107f

19. Almiron-Roig E, Tsiountsioura M, Lewis HB, Wu J, Solis-Trapala I, Jebb SA. Large portion sizes increase bite size and eating rate in overweight women. Physiol Behav. 2015;139:297-302. doi:10.1016/ j.physbeh.2014.11.041
20. Slyper AH. A paradigm shift for the prevention and treatment of individual and global obesity. Diabetes, Metab Syndrm Obes. 2018;11:855-861. doi:10.2147/DMSO.S183777

21. Gibbons C, Hopkins M, Beaulieu K, Oustric P, Blundell JE. Issues in measuring and interpreting human appetite (satiety/satiation) and its contribution to obesity. Curr Obes Rep. 2019;8:77-87. doi:10.1007/ s13679-019-00340-6

22. Sadoul BC, Schuring EA, Mela DJ, Peters HP. The relationship between appetite scores and subsequent energy intake: an analysis based on 23 randomized controlled studies. Appetite. 2014;83:153-159. doi:10.1016/j.appet.2014.08.016

23. Doulah A, Yang X, Parton J, Higgins JA, McCrory MA, Sazonov E. The importance of field experiments in testing of sensors for dietary assessment and eating behavior monitoring. Conf Proc IEEE Eng Med Biol Soc. 2018:5759-5762. doi:10.1109/EMBC.2018.8513623

\section{Publish your work in this journal}

Diabetes, Metabolic Syndrome and Obesity: Targets and Therapy is an international, peer-reviewed open-access journal committed to the rapid publication of the latest laboratory and clinical findings in the fields of diabetes, metabolic syndrome and obesity research. Original research, review, case reports, hypothesis formation, expert opinion and commentaries are all considered for publication. The manuscript management system is completely online and includes a very quick and fair peer-review system, which is all easy to use. Visit http://www.dovepress.com/testimonials.php to read real quotes from published authors. 